\title{
Technology Acceptance Model Validation in an Educational Context: A Longitudinal Study of ERP System Use
}

\author{
Elizabeth E. Grandón ${ }^{1 \star}$, Beatriz Díaz-Pinzón ${ }^{2}$, Simha R. Magal ${ }^{3}$, Karina Rojas-Contreras ${ }^{1}$
}

\author{
${ }^{1}$ Facultad de Ciencias Empresariales, Universidad del Bío-Bío, Concepción, CHILE \\ ${ }^{2}$ Facultad de Ciencias Económicas, Universidad Nacional de Colombia, Bogotá, COLOMBIA \\ ${ }^{3}$ Robinson College of Business, Georgia State University, Atlanta, Georgia, USA \\ *Corresponding Author: egrandon@ubiobio.cl
}

Citation: Grandón, E. E., Díaz-Pinzón, B., Magal, S. R., Rojas-Contreras, K. (2021). Technology Acceptance Model Validation in an Educational Context: A Longitudinal Study of ERP System Use. Journal of Information Systems Engineering and Management, 6(1), em0134. https://doi.org/10.29333/jisem/9582

\section{ARTICLE INFO}

Published: 17 Jan. 2021

\begin{abstract}
Although Enterprise Resource Planning (ERP) systems have been implemented and extensively studied in corporate contexts, there is a lack of research that focuses on educational settings. This study intends to fill this gap by validating the technology acceptance model (TAM) in an educational context to better understand the factors that influence students' intention to use ERP systems. The research model was empirically tested using data collected from students enrolled in ERP courses in two public universities in different countries at two points in time. The results of this longitudinal, cross-cultural study indicate that perceived ease of use and perceived usefulness predicts behavioral intention, with perceived usefulness the strongest predictor. As students use the ERP system in class, their perceptions of ease of use, usefulness, and intention to use the system are more favorable. Along the same lines, students with previous experience in ERP systems have more favorable perceptions of ease of use and usefulness than students with no experience. Contributions of the study and recommendations for future research are proposed.
\end{abstract}

Keywords: ERP systems, technology adoption, TAM model, longitudinal study, educational context

\section{INTRODUCTION}

Organizations have used Enterprise Resource Planning (ERP) systems to support their business processes for over forty years (Mohammad et al., 2002; Strong et al., 2006). Given the significant investment required to implement and use ERP systems, organizations have sought to ensure successful adoption and use. One body of research on ERP systems has attempted to identify the factors that influence adoption and use. Key factors identified relate to executive commitment, understanding of business processes, proficiency in the use of technologies, adequate training in the use of systems, learning and predisposition for change, and reengineering and integration of business processes (Pinto et al, 2017). A meta-analysis conducted by Ramírez and García (2005), revealed that factors related to education and training were identified most often as leading to successful implementation of ERP systems. This has implications for educational institutions and should inform university curricula and approaches to teaching about ERP system. Most graduates will likely encounter ERP systems in their profession either as end-users or as system administrators, and employers increasingly require knowledge of and hands-on experience with ERP systems (Vluggen and Bollen, 2005). Institutions of higher education are well advised to incorporate ERP-related topics in their curricula.

Over the last two decades, many universities have incorporated ERP-related content in their academic programs (Ramírez and García, 2005; Strong et al., 2006). However, few have included hands-on experiences for students. Vluggen and Bollen (2005) have identified several obstacles, such as resistance to change curricula, lack of resources, challenges with forming multidisciplinary teams of instructors for integrated teaching, and technical challenges of maintaining needed infrastructure. Some of these obstacles are associated with acceptance of new technologies (Vluggen and Bollen, 2005).

The Technology Acceptance Model (TAM) (Davis, 1989) is a widely used model to predict intention and use of new systems and technologies. This is largely due to its simplicity and predictive power. However, much of the TAM research is in an organizational context (Al-Jabri and Roztocki, 2015; Kumar and Van Hillsgersberg, 2000; Lodhi et al., 2016) and there are few studies that have validated the model in an educational context. The purpose of this research is to validate the TAM model in an educational context. 


\section{THEORETICAL FRAMEWORK}

\section{ERP Systems}

ERP systems are "configurable information systems packages that integrate information and information-based processes within and across functional areas in an organization" (Kumar and Van Hillsgersberg, 2000: 23). They support cross-functional processes across an enterprise and serve as platforms for additional applications related to supply chain management, customer resource management and analytics.

ERP systems are of significant value to educational institutions, especially business schools. The integrated nature of ERP systems offer a mechanism for business schools to provided integrated knowledge of processes across functional areas. Previous research on the use of ERP systems in curricula are summarized in Table 1.

Table 1. Previous ERP studies - Educational contexts

\begin{tabular}{|c|c|c|c|c|}
\hline Authors & Type of design & Culture & Theoretical background & Data collection method \\
\hline Cronan and Douglas (2012) & Longitudinal & One culture (US) & $\begin{array}{c}\text { Partial TAM (Sternad and } \\
\text { Bobek, 2013) * }\end{array}$ & Structured questionnaire \\
\hline Seethamraju (2007) & Cross-sectional & One culture (US) & - & Survey questionnaire \\
\hline Johnson et al. (2004) & Cross-sectional & One culture (US) & - & Case study \\
\hline Alshare and Lane (2011) & Cross-sectional & One culture (US) & UTAUT (Venkatesh, 2000) & Survey questionnaire \\
\hline Johansson et al. (2014) & Cross-sectional & One culture (US) & $\begin{array}{l}\text { Bloom's taxonomy for learning } \\
\text { objectives }\end{array}$ & $\begin{array}{c}\text { Teaching case, reflective } \\
\text { workshop }\end{array}$ \\
\hline Scholtz et al. (2017) & Cross-sectional & One culture (South Africa) & $\begin{array}{c}\text { Partial TAM (Sternad and } \\
\text { Bobek, 2013) * }\end{array}$ & Survey questionnaire \\
\hline
\end{tabular}

*the study did not measure behavioral intention

\section{Technology Aceptance Model (TAM)}

The TAM model postulates that perceived usefulness (PU) and perceived ease of use (PEOU) are key antecedents of a person's behavioral intention to use a technology (Davis, 1989). PU is defined as 'the degree to which a person believes that using a particular system would enhance his or her job performance' (Davis, 1989: p. 320). In contrast, PEOU refers to 'the degree to which a person believes that using a particular system would be free of effort' (Davis, 1989: p. 320). Specifically, the TAM model postulates that there is a greater likelihood of using a technology if an individual perceives the technology to be easy to use and useful in performing job-related tasks. Further, the model indicates that PEOU has an indirect impact on intention to use a technology by influencing perception of usefulness.

Numerous studies have validated the TAM model in a variety of contexts across numerous technologies. Some of the key studies are summarized in Table 2.

Table 2. Previous ERP studies - Organizational contexts

\begin{tabular}{|c|c|c|c|c|}
\hline Authors & Type of design & Culture & Theoretical background & Data collection method \\
\hline Palomino and Whitley (2007) & Cross-sectional & $\begin{array}{c}\text { Cross-cultural (Colombia and } \\
\text { Switzeland) }\end{array}$ & Hofstede (2001) & $\begin{array}{l}\text { Interviews, document } \\
\text { analysis }\end{array}$ \\
\hline Sheu et al. (2003) & Cross-sectional & $\begin{array}{c}\text { Cross-cultural } \\
\text { (US and Taiwanese manufact. firms) }\end{array}$ & - & $\begin{array}{l}\text { Direct observation, } \\
\text { structured interviews }\end{array}$ \\
\hline Livermore and Rippa (2011) & Cross-sectional & Cross-cultural (US and Italy) & - & Two case studies \\
\hline Lodhi et al. (2016) & Cross-sectional & One culture (Pakistani companies) & $\begin{array}{l}\text { TAM (Sternad and Bobek, } \\
2013)^{*}\end{array}$ & Structured questionnaire \\
\hline Sternad and Bobek (2013) & Cross-sectional & One culture (Slovenian companies) & $\begin{array}{l}\text { TAM (Sternad and Bobek, } \\
2013)^{\star}\end{array}$ & Survey questionnaire \\
\hline Al-Jabri and Roztocki (2015) & Cross-sectional & $\begin{array}{l}\text { One culture (Saudi Arabian } \\
\text { companies) }\end{array}$ & $\begin{array}{c}\text { Extended TAM (Sternad and } \\
\text { Bobek, 2013)* }\end{array}$ & $\begin{array}{l}\text { Online Survey } \\
\text { questionnaire }\end{array}$ \\
\hline Soto-Acosta et al. (2013) & Cross-sectional & $\begin{array}{c}\text { One culture } \\
\text { (Malaysian manufact. firm) }\end{array}$ & $\begin{array}{c}\text { Extended TAM (Sternad and } \\
\text { Bobek, 2013)* }\end{array}$ & Survey questionnaire \\
\hline
\end{tabular}

A review of the research summarized in Table 1 and Table 2 indicates that the vast majority of the studies are cross-sectional, that is, the data are collected at one point in time. In addition, most of the studies, especially those in an educational context, are limited to data from one culture. As previously noted, the purpose of this research is to validate the TAM model in an educational context. Going further, we will attempt to validate the model using a longitudinal, a cross-cultural setting. We propose the following hypotheses:

H1: The perceived usefulness of an ERP system is positively related to the intention to use the system by students

H2: The perceived ease of use of an ERP system is positively related to the intention to use the system by students

H3: The perceived ease of use of an ERP system is positively related to the perceived usefulness of the system by students

As Johanssen et al. (2014) points out, applying procedural knowledge, in this case having hands-on exposure to an ERP system, facilitates the students' ability to understand, analyze, and evaluate the ERP system. Therefore, it is expected that the students will become more knowledgeable as they use the system. In addition, prior literature has shown that previous experience might affect IT adoption (Salahshour et al, 2018; Venkatesh et al, 2003). Thus, we extended Grandon et al. (2020) study by focusing on 
students' perceptions during the educational process and taking into account previous experience. Accordingly, we offer the following additional hypotheses:

H4: As students use an ERP system in class, their perceptions of ease of use, usefulness, and intention to use the system will be more favorable

H5: Students with previous experience with ERP systems, will have more favorable perceptions of ease of use and usefulness than students with no experience with ERP systems.

\section{METHODOLOGY}

The study was conducted at two public universities, one in Chile and one in Colombia, where the difficulties cited by Vluggen and Bollen (2005), and stated in the Introduction section, were overcome. Both universities incorporated elective ERP classes in the curriculum, acquired licenses to use ERP software in the classroom, have well-trained instructors for the integrated teaching of ERP systems, and maintain the required technical infrastructure for the use of the ERP. The students belong to Colleges of Business and Engineering. The objective of the class is for the students to be exposed to executing business processes and to understand how the integration of a company's processes occurs with the use of the SAP/R3 ERP system. Both universities belong to the SAP University Alliances Program and they used the same class material ("Integrated Business Process with ERP Systems" book (Magal and Word, 2012), where concepts related to financial accounting, procurement, and fulfillment processes, and their integration are covered. Students had the opportunity to use an SAP ERP system in the lab each week and use the Global Bike Inc. (Magal and Word, 2012), case study material.

A measurement instrument was developed based on the scales proposed by Davis (1989), where the perceptions of students from both universities towards the ERP system were evaluated. Perceived ease of use, perceived usefulness, and behavioral intention were measured using a seven-point Likert scale where 1 represents strong agreement with the statement, and 7 represents strong disagreement. The questionnaire was administered to students at two points in time during the semester. Figure 1 shows the interventions performed and the times when the data was collected. At time 1 data was collected after covering the concepts and executing, in the laboratory, the processes of financial accounting and procurement, while at time 2, data was collected after covering the concepts and executing the fulfillment and process integration.

The study utilized a multivariate data analysis, the Partial Least Squares - Structural Equation Modeling (PLS-SEM) technique. SmartPLS 3.2.8 statistical software (Ringle et al, 2015) was used to perform the statistical analysis.

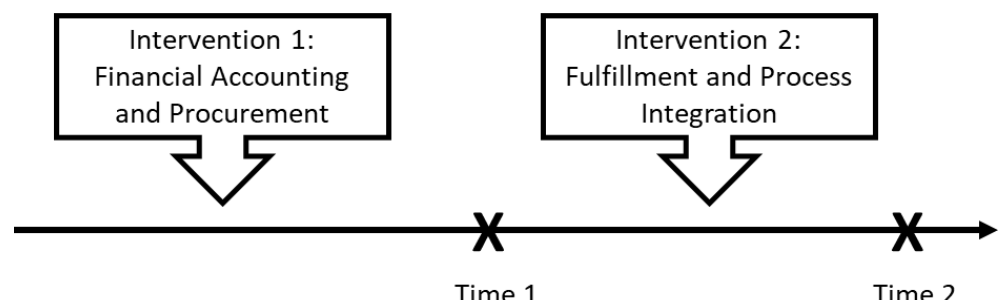

Figure 1. Longitudinal Design

\section{RESULTS}

\section{Demographic Information}

For time 1, 93 students participated in the study ( 45 Chileans and 48 Colombians). At time 2, 109 students participated (55 Chileans and 54 Colombians). As in any longitudinal study, there is a drop-off rate since some of the students did not attend the class the day surveys were administered. Table 3 provides the demographic information collected at both times, without differentiating the student's country of origin. Students belong to Business and Accounting majors (approximately 60\%) and Computer and Industrial Engineering majors (about 32\%). On average, $71.4 \%$ of the students had no previous experience in using any ERP system. 
Table 3. Student demographic information - Time 1 and 2

\begin{tabular}{|c|c|c|c|c|c|}
\hline & \multirow{2}{*}{ Category } & \multicolumn{2}{|c|}{ Time 1} & \multicolumn{2}{|c|}{ Time 2} \\
\hline & & No. & $\%$ & No. & $\%$ \\
\hline \multirow{2}{*}{ Gender } & Female & 56 & 60.2 & 62 & 56.9 \\
\hline & Male & 37 & 39.8 & 47 & 43.1 \\
\hline \multirow{3}{*}{ Age } & $18-21$ & 45 & 48.4 & 51 & 46.8 \\
\hline & $22-25$ & 41 & 44.1 & 49 & 45.0 \\
\hline & $26-30$ & 7 & 7.5 & 8 & 7.3 \\
\hline \multirow{5}{*}{ Major } & Business & 35 & 37.6 & 40 & 36.7 \\
\hline & Accounting & 22 & 23.7 & 25 & 22.9 \\
\hline & Computer Engineering & 13 & 14.0 & 23 & 21.1 \\
\hline & Industrial Engineering & 16 & 17.2 & 12 & 11.0 \\
\hline & Other & 7 & 7.5 & 9 & 8.3 \\
\hline \multirow{2}{*}{ ERP experience } & Yes & 24 & 25.8 & 33 & 30.3 \\
\hline & No & 68 & 73.1 & 76 & 69.7 \\
\hline TOTAL & & 93 & $100 \%$ & 109 & $100 \%$ \\
\hline
\end{tabular}

\section{Group Difference}

Since, in both countries, the course was taught following the same methodology, using the same materials and similar assessments, and considering that the students had very similar demographic characteristics, a comparison of means was performed to determine whether both samples (Chilean and Colombian) had significant differences. As none of the samples exhibited a normal distribution (the Kolmogorov-Smirnov and Shapiro-Wilk tests yielded a bilateral asymptotic significance $p$ value less than 0.05), non-parametric tests were used (Hair et al., 2014). Both Mann-Whitney and Kolmogorov-Smirnov tests yielded a significance $p$-value $>0.05$, so it could be concluded that there are no significant differences between the two groups of students. This result may go in line with Hofstede's study of cultural differences among countries (Hofstede, 2001). Both Chile and Colombia score similar in some dimensions, particularly in the uncertainty avoidance dimension ( 86 and 80 respectively). Uncertainty avoidance is defined as the extent to which the members of a culture feel threatened by ambiguous or unknown situations and have created beliefs and institutions that try to avoid these. The adoption of new, unfamiliar technologies as ERP systems may bring uncertainty to both groups of students. Therefore, for the rest of the statistical analysis, both samples were combined to compare the differences in student perceptions at times 1 and 2 and validate the proposed model.

\section{Validation of the TAM Model}

To vatidate hypotheses $\mathrm{H} 1, \mathrm{H} 2$, and $\mathrm{H} 3$ concerning the TAM model shown in Figure 2, we utilized the PLS technique. This approach is defined by two models: the measurement model and the structural model.

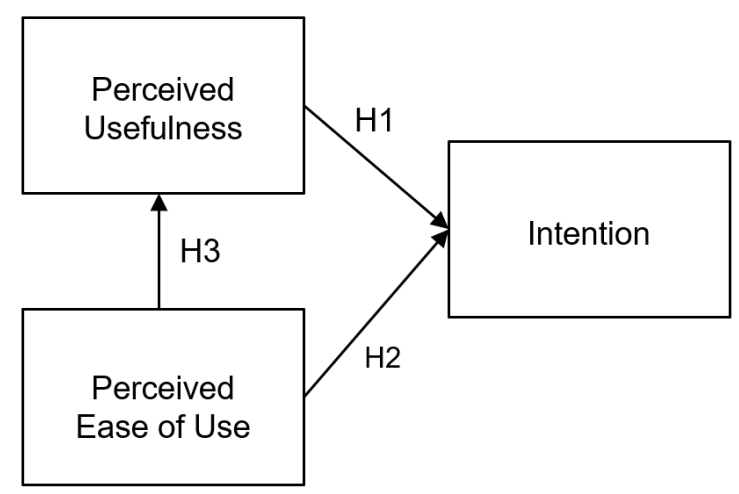

Figure 2. Research Model

\section{Measurement Model}

The psychometric characteristics of the instrument used at two points in time were analyzed. Using the partial least squares (PLS) technique, the measurement model was analyzed, and the convergent validity (reliability/internal consistency) and discriminating validity of the model's constructs were calculated. Convergent validity is the degree to which an indicator is positively correlated with alternative indicators of the same construct (Hair et al, 2014). To determine the convergent validity of the constructs that make up the model, Cronbach's alfa, a measure of composite reliability, and the average variance extracted (AVE) from each construct (latent variables of behavioral intention, perceived ease of use, and perceived usefulness) were calculated. Table 4 shows the corresponding values for the three constructs for both time 1 and time 2 after running the PLS algorithm. 
Table 4. Convergent validity

\begin{tabular}{ccccccc}
\hline & \multicolumn{3}{c}{ Time 1 } & \multicolumn{2}{c}{ Time 2 } \\
\cline { 2 - 6 } & Cronbach's Alpha & Composite reliability & AVE & Cronbach's Alpha & Composite reliability & AVE \\
\hline BI & 0.978 & 0.986 & 0.959 & 0.979 & 0.986 \\
\hline PEOU & 0.942 & 0.958 & 0.851 & 0.934 & 0.959 \\
\hline PU & 0.974 & 0.981 & 0.928 & 0.964 & 0.834 \\
\hline
\end{tabular}

The Cronbach's alphas are all greater than 0.9, indicating a high internal consistency in the latent variables of the model. Similarly, the values associated with the composite reliability of the constructs exceed the values suggested by Hair et al. (2014) $(>0.70)$. The results obtained for the average variance extracted were also higher than those recommended by Fornell and Larcker (1981) (>0.50).

To correctly assess the individual reliability of the indicators concerning their respective construct, it is required that the loads exceed the value 0.70 (Chin, 1998). In this case, the values of all loads exceed the indicated value. Compliance with the individual reliability of the indicators is shown in Table 5.

Table 5. Outer loadings for each construct

\begin{tabular}{|c|c|c|c|c|c|c|c|c|c|c|c|}
\hline \multicolumn{6}{|c|}{ Time 1} & \multicolumn{6}{|c|}{ Time 2} \\
\hline \multicolumn{2}{|c|}{ BI } & \multicolumn{2}{|c|}{ PEOU } & \multicolumn{2}{|c|}{ PU } & \multicolumn{2}{|c|}{ BI } & \multicolumn{2}{|c|}{ PEOU } & \multicolumn{2}{|c|}{ PU } \\
\hline Item & Load & Item & Load & Item & Load & Item & Load & Item & Load & Item & Load \\
\hline BI1 & 0.981 & PEOU1 & 0.913 & PU1 & 0.976 & Bl1 & 0.980 & PEOU1 & 0.913 & PU1 & 0.962 \\
\hline $\mathrm{B} 12$ & 0.986 & PEOU2 & 0.939 & PU2 & 0.972 & $\mathrm{~B} \mid 2$ & 0.987 & PEOU2 & 0.915 & PU2 & 0.971 \\
\hline \multirow[t]{2}{*}{$\mathrm{BI} 3$} & 0.971 & PEOU3 & 0.903 & PU3 & 0.984 & $\mathrm{BI} 3$ & 0.970 & PEOU3 & 0.923 & PU3 & 0.964 \\
\hline & & PEOU4 & 0.935 & PU4 & 0.919 & & & PEOU4 & 0.903 & PU4 & 0.905 \\
\hline
\end{tabular}

The discriminant validity indicates the degree to which one construct is truly different from another. Following the recommendations of Hair et al. (2014), the discriminant validity was determined from the cross-loadings analysis of the indicators and the Fornell-Larcker criterion. The cross-loading analysis (Table 6) indicates that the three constructs have higher loads in the indicators associated with the construct than in the other constructs. On the other hand, Fornell-Larcker's criterion states that the square root of each construct's AVE should be greater than the highest correlation with another construct (Fornell and Larcker, 1981). Table 7 shows the discriminant validity associated with the Fornell-Larcker criterion for both times.

Table 6. Cross-loads of latent variables

\begin{tabular}{|c|c|c|c|c|c|c|}
\hline & \multicolumn{3}{|c|}{ Time 1} & \multicolumn{3}{|c|}{ Time 2} \\
\hline & BI & PEOU & PU & BI & PEOU & PU \\
\hline BI1 & 0.981 & 0.750 & 0.915 & 0.980 & 0.759 & 0.896 \\
\hline $\mathrm{B} 12$ & 0.986 & 0.772 & 0.902 & 0.987 & 0.766 & 0.882 \\
\hline $\mathrm{BI3}$ & 0.971 & 0.751 & 0.855 & 0.970 & 0.712 & 0.808 \\
\hline PEOU1 & 0.800 & 0.913 & 0.797 & 0.728 & 0.913 & 0.741 \\
\hline PEOU2 & 0.780 & 0.939 & 0.758 & 0.756 & 0.915 & 0.766 \\
\hline PEOU3 & 0.590 & 0.903 & 0.559 & 0.649 & 0.923 & 0.628 \\
\hline PEOU4 & 0.641 & 0.935 & 0.655 & 0.633 & 0.903 & 0.580 \\
\hline PU1 & 0.917 & 0.755 & 0.976 & 0.881 & 0.710 & 0.962 \\
\hline PU2 & 0.898 & 0.728 & 0.972 & 0.836 & 0.723 & 0.971 \\
\hline PU3 & 0.890 & 0.756 & 0.984 & 0.833 & 0.750 & 0.964 \\
\hline PU4 & 0.797 & 0.701 & 0.919 & 0.803 & 0.672 & 0.905 \\
\hline
\end{tabular}

Table 7. Discriminatory validity (Fornell-Larcker criterion)

\begin{tabular}{cccccc}
\hline & & Time 1 & & Time 2 \\
\hline & BI & PEOU & PU & BI & PEOU \\
\hline BI & $\mathbf{0 . 9 7 9}$ & & & $\mathbf{0 . 9 7 9}$ & \\
\hline PEOU & 0.774 & $\mathbf{0 . 9 2 2}$ & & 0.762 & $\mathbf{0 . 9 1 4}$ \\
\hline PU & 0.910 & 0.763 & $\mathbf{0 . 9 6 3}$ & 0.882 & 0.751 \\
\hline
\end{tabular}




\section{Structural Model}

The analysis of the structural model is based on the adjustment of the model to the data to obtain the best estimates of the parameters, while maximizing the explained variance of the endogenous latent variables (Hair et al., 2014). In this case, the coefficient of determination $R^{2}$ is analyzed at both times in the data collection process. The $R^{2}$ at time 1 is 0.84 while at time 2 is 0.80 (Figures 3 and 4 respectively). Both values are satisfactory according to typical acceptance criteria (Hair et al., 2014). This indicates that the intention to use ERP systems by university students from Chile and Colombia is explained by $84 \%$ and $80 \%$, respectively. Perceived usefulness is explained by $58 \%$ in time 1 and $56 \%$ in time 2 .

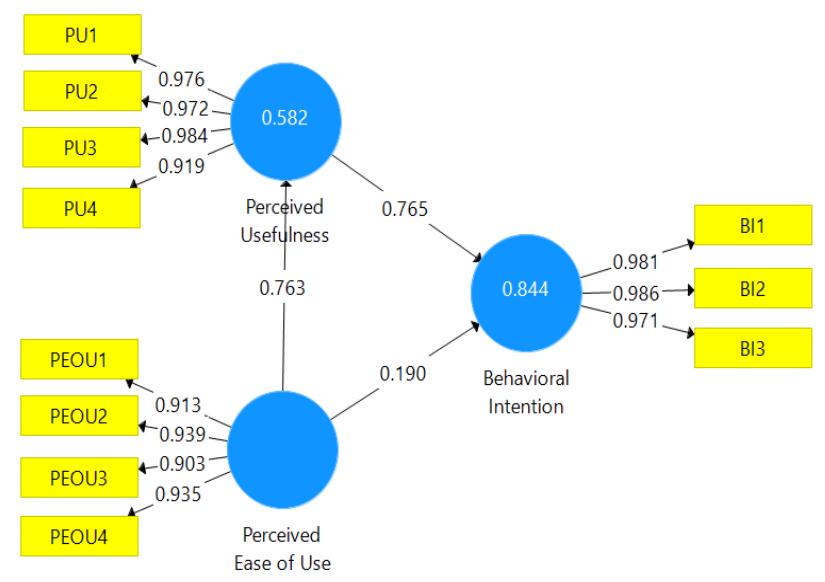

Figure 3. Results from PLS algorithm - Time 1

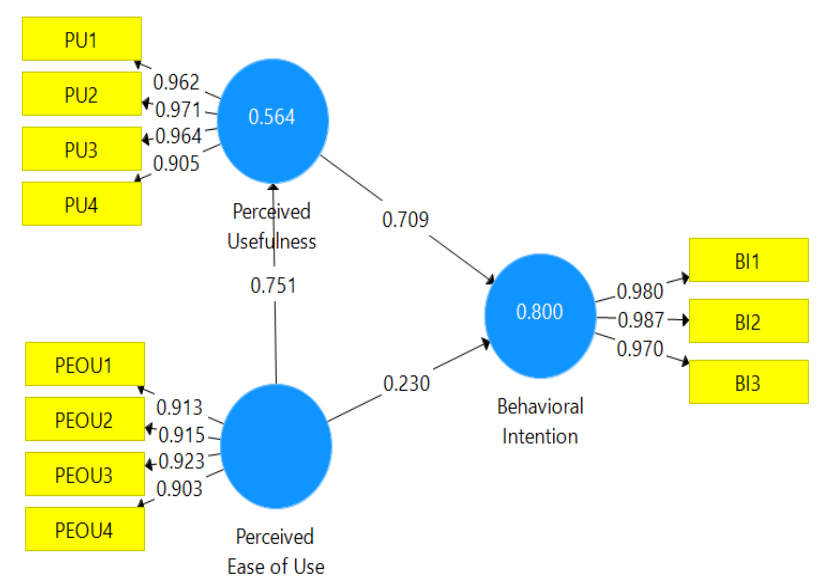

Figure 4. Results from PLS algorithm - Time 2

In addition, path coefficients and t-statistics at both times were analyzed using the bootstrapping technique. Table 8 shows these indicators plus the values associated with each latent variable.

Table 8. Bootstrapping results

\begin{tabular}{ccccccc}
\hline & \multicolumn{3}{c}{ Time 1 } & \multicolumn{2}{c}{ Time 2 } \\
\hline Relationships & $\boldsymbol{\beta}$ coef. & t-statistics & p-value & $\boldsymbol{\beta}$ coef. & t-statistics & p-value \\
\hline PEOU $\rightarrow$ BI & 0.190 & 2.434 & 0.015 & 0.230 & 0.839 \\
\hline PEOU $\rightarrow$ PU & 0.763 & 16.666 & 0.000 & 0.751 & 16.175 \\
\hline PU $\rightarrow$ B & 0.765 & 10.638 & 0.000 & 0.709 & 9.685 & 0.000 \\
\hline
\end{tabular}

Figures 5 and 6 presents the research model with indication of the significance of the path coefficients for each time of the data collection process. 


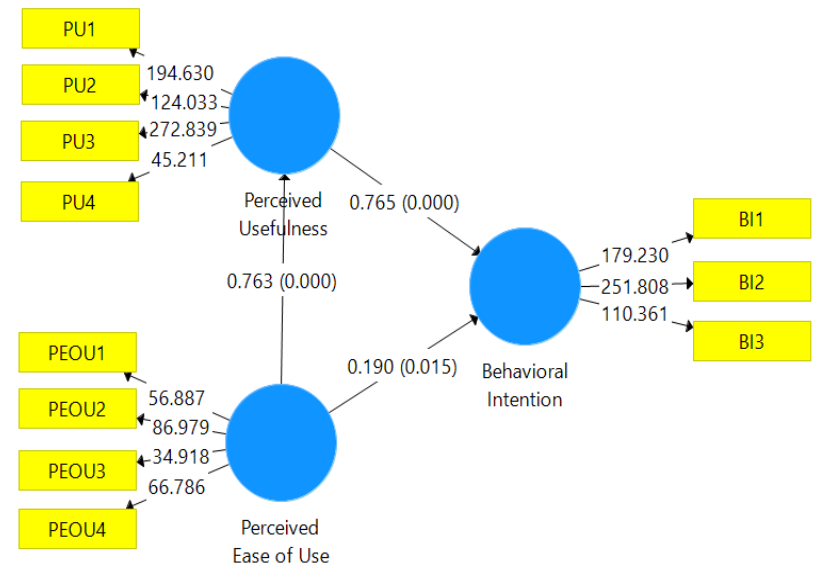

Figure 5. Results after running Bootstrapping - Time 1

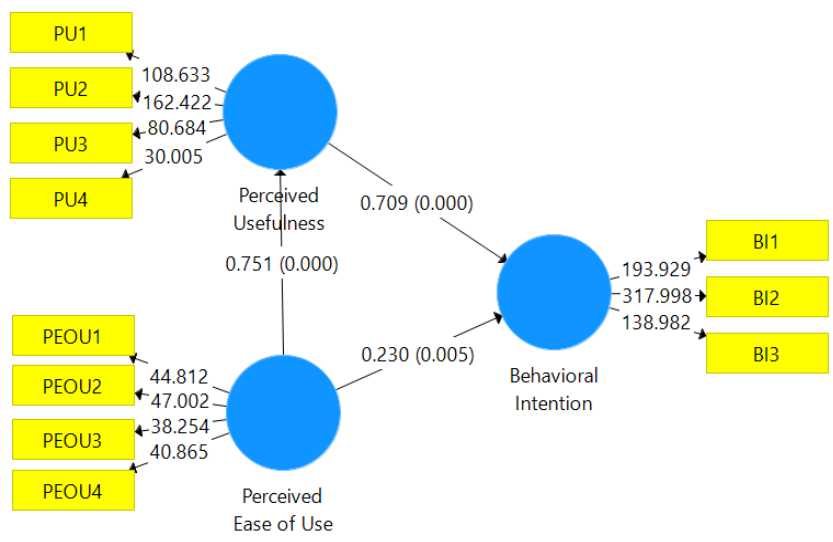

Figure 6. Results after running Bootstrapping - Time 2

The intention to use an ERP system by students is explained by their perceptions of ease of use ( $\beta=0.190 ; p<0.05$ at time 1 , and $\beta=0.230 ; p<0.05$ at time 2$)$ and usefulness $(\beta=0.765 ; p<0.05$ at time 1 , and $\beta=0.709 ; p<0.05$ at time 2$)$. In turn, perceptions of ease of use of the system explain perceived usefulness $(\beta=0.763 ; p<0.05$ at time 1 , and $\beta=0.751 ; p<0.05$ at time 2 ). Therefore, hypotheses $\mathrm{H} 1, \mathrm{H} 2$, and $\mathrm{H} 3$ are supported.

\section{Students Perceptions of ERP Systems}

Based on the average values of raw data, it can be seen in Table 9 that students 'perceptions of ease of use, usefulness, and intention to use the ERP system decreases as the students have hands-on experience during the semester. This indicate that their perceptions are more favorable in time 2 than in time 1 (see Appendix A for the items included in the questionnaire and anchors). These results confirm hypothesis $\mathrm{H} 4$. The higher difference is in perceptions of usefulness $(0.45)$ followed by behavioral intention (0.29).

Table 9. Averages of students perceptions of usefulness, ease of use, and behavioral intention- Time 1 and 2

\begin{tabular}{cccc}
\hline Perceptions & Average at Time 1 & Average at Time 2 & Difference \\
\hline PU & 3.06 & 2.61 & 0.45 \\
\hline PEOU & 3.54 & 3.32 & 0.22 \\
\hline BI & 3.17 & 2.88 & 0.29 \\
\hline
\end{tabular}

We also tested whether previous experience plays a role in students' perceptions. As can be seen in Table 10, students with previous experience have more favorable perceptions toward the usefulness and ease of use of the ERP system. They also have a stronger agreement with the intention to use the system than those with no experience. These results confirm hypothesis $\mathrm{H} 5$.

Table 10. Average values considering previous experience - Time 1 and 2

\begin{tabular}{|c|c|c|c|}
\hline \multicolumn{4}{|c|}{ Perceived Ease of use (PEOU) } \\
\hline Experience & Time 1 & Time 2 & Difference \\
\hline NO & 3.67 & 3.38 & 0.29 \\
\hline YES & 3.19 & 3.13 & 0.06 \\
\hline \multicolumn{4}{|c|}{ Perceived Usefulness (PU) } \\
\hline Experience & Time 1 & Time 2 & Difference \\
\hline NO & 3.18 & 2.81 & 0.38 \\
\hline YES & 2.77 & 2.76 & 0.01 \\
\hline
\end{tabular}




\section{DISCUSSION}

Even though students considered in this study come from different countries, their demographics and perceptions towards ERP systems are similar. Cultural differences seem to not play a role in this study. It was found that there are no statistically significant differences between the demographic of the two student groups.

The results indicate that, as in organizational contexts, the TAM model is suitable to explain students' intention to use ERP systems in educational settings. These findings are similar to the ones obtained by Soto et al. (2013), and Al-Jabri and Roztocki (2015) who found that perceived usefulness and perceived ease of use influence the attitude of ERP users in a company setting which in turn influence the intention to use it and the symbolic adoption respectively.

Furthermore, the results indicate that when systems are perceived to be easy to use and understand, they would be viewed as more useful use $(\beta=0,763 ; p<0.05$ at time 1 , and $\beta=0,751 ; p<0.05$ at time 2$)$. This finding is also consistent with previous research in organizational contexts (Soto-Acosta et al., 2013; Sternad and Zabukovsek, 2013) and educational contexts (Alshare \& Lane, 2011). Particularly, perceived usefulness influences the intention to use the ERP systems more than perceived ease of use ( $\beta=0,765$ vs. $\beta=0,190$ at time $1 ; \beta=0,709$ vs. $\beta=0,230$ at time 2 ). Students recognize that understanding ERP concepts is useful for future job opportunities.

Additionally, the results indicate that, as students have more hands-on experience using the ERP system during the semester, their perceptions of usefulness and ease of use are more favorable. After completing the class, they have stronger beliefs that the ERP system will be useful for their work, and that it will allow them to accomplish tasks more quickly, thereby increasing their productivity at work. Similarly, as students become more knowledgeable about the ERP system, they have stronger beliefs that the system is easy to use and understand. The difference between perceptions of ease of use is smaller than that of usefulness since the students already used the ERP system in time 1 (financial accounting and procurement processes). At time 2, they executed fulfillment and process integration, giving them more experience to better understand business processes in an organizational context.

\section{CONCLUSIONS}

To date, little has been done to theorize the essential predictors of ERP adoption in educational contexts. Using the TAM model as theoretical underpinning, this study validated that students' perceptions are important in determining their intention to use ERP systems in the future. The TAM model was empirically tested using data collected from students enrolled in ERP courses in two countries and at two points in time.

The results of the study provide some theoretical contributions. It has validated that the TAM model can be applied to study the intention to use ERP systems by students. Universities should incorporate ERP courses in their curricula for the students to understand business process integration better. As students understand the functioning of an ERP system, they will find it easy to use and useful, which, in turn, will influence their intention to use it.

There are implications for practice as well. Organizations implement an ERP system to realize the benefits of such systems. These benefits only are realized when users understand the value of these systems and use them. This study indicates that graduates of programs with a strong ERP component understand the value of such systems (usefulness) and have a firm intention to use these systems. Therefore, organizations that recruit graduates from such academic programs are likely to realize the benefits of ERP systems faster than those who do not.

The limitation of this study corresponds to the sample size. However, as a longitudinal and cross-cultural study, it is possible to use PLS-SEM, which can be applied to smaller samples (Wong, 2010). Therefore, this limitation is partly relieved.

Future research could consider other factors that may influence the intention to use ERP systems and moderator variables, such as students' majors, experience, or gender, that might increase the model's explanation power. Further studies could focus on determining students' perceptions and knowledge gained before having any hands-on experience (time 0 ) and comparing their perceptions before and after completing the course.

\section{REFERENCES}

Al-Jabri, I. M. and Roztocki, N. (2015) Adoption of ERP systems: Does information transparency matter?, Telematics and Informatics, 32(2), 300-310. https://doi.org/10.1016/j.tele.2014.09.005

Alshare, K. A. and Lane, P. L. (2011). Predicting Student-Perceived Learning Outcomes and Satisfaction in ERP Courses: An Empirical Investigation. Communications of the Association for Information Systems, 28(34), 571-584. https://doi.org/10.17705/1CAIS.02834

Chin, W. W. (1998). The partial least squares approach for structural equation modeling. In G. A. Marcoulides (Ed.), Methodology for business and management. Modern methods for business research (pp. 295-336). Lawrence Erlbaum Associates Publishers.

Cronan, T. P. and Douglas, D. E. (2012) A student simulation game: a longitudinal study. Journal of Computer Information Systems, 53(1), 3-13. https://doi.org/10.1080/08874417.2012.11645591 
Davis, F (1989). Perceived Usefulness, Perceived Ease of Use, and User Acceptance of Information Technology. MIS Quarterly, 13(3), 319. https://doi.org/10.2307/249008

Fornell, C. and Larcker, D.F. (1981). Evaluating structural equation models with unobservable variables and measurement error. Journal of Marketing Research, 18, 39-50. https://doi.org/10.2307/3151312

Grandón, E. E., Magal, S. R., Pinzón, B. H. D. and Rojas, K. P. (2020). Validation of an ERP system acceptance model among Latin American students: A longitudinal study in Chile and Colombia. 2020 15th Iberian Conference on Information Systems and Technologies (CISTI), Sevilla, Spain, pp. 1-6, https://doi.org/10.23919/CISTI49556.2020.9140891

Grandón, E., Ramírez-Correa, R. and Rojas, K. (2018). Use of business process chage theory to examine enterprise resource planning adoption in Chile. Interciencia, 43(10), 716-722.

Hair, J. F., Hult, T. M., Ringle, C. M. and Sarstedt, M. A. (2014). A primer on partial least square structural equation modeling (PLSSEM). Los Angeles: SAGE.

Hofstede, G. (2001). Culture's Consequences: Comparing Values, Behaviors, Institutions, and Organizations Across Nations (2nd ed.). Sage, Thousand Oaks, CA.

Johansson, L., Zimmerman, E. and Rehnström, C. (2014). Facilitating students' learning outcome of business processes using an ERP. Proceedings of the Americas Conference on Information Sistems (AMCIS), Savannah, USA.

Johnson, T., Lorents, A. C., Morgan, J. and Ozmun, J. (2004). A customized ERP/SAP Model for Business Curriculum integration. Journal of Information Systems Education, 15(3), 245-253.

Kumar, K. and Van Hillsgersberg, J. (2000). ERP experiences and evolution. Communications of the ACM, 43(4), $23-26$. https://doi.org/10.1145/332051.332063

Livermore, C. R. and Rippa, P. (2011) ERP Implementation: A Cross-Cultural Perspective. Journal of Global Information Technology Management, 14(3), 5-26. https://doi.org/10.1080/1097198X.2011.10856541

Lodhi, R. N., Abdullah, M. and Shahzad, A. (2016). An empirical investigation of the effectiveness of ERP Quality: evidence from corporatesector of Pakistan. Journal of Quality and Technology Management, 12(2), 71-88.

Magal, S. and Word, J. (2012). Integrated business processes with ERP sytems. Wiley and Sons Inc. USA

Mohammad, R., Hossain, L. and Patrick, J. D. (2002). The evolution of ERP systems: A historical perspective. Chapter 1 in Enterprise Resource Planning: Global Opportunities and Challenges, 1-16.

Palomino, M. A. and Whitley, E. A. (2007). The effects of national culture on ERP implementation: a study of Colombia and Switzerland. Enterprise Information Systems, 1(3), 301-325. https://doi.org/10.1080/17517570701504294

Pinto, M., Ramírez-Correa, P. and Grandón, E. (2017). Antecedentes del éxito de los sistemas de planificación de recursos empresariales en las grandes empresas Chilenas: Un modelo factorial exploratorio. Información Tecnológica, 28(3), $139-146$. https://doi.org/10.4067/S0718-07642017000300015

Ramírez, P. and García, R. (2005). Meta-analysis on the implementation of ERP systems, Journal of Information Systems and Technology Management, 2(3), 245-273. https://doi.org/10.4301/S1807-17752005000300002

Ringle, C. M., Wende, S. and Becker, J. M. (2015). SmartPLS 3. Boenningstedt: SmartPLS GmbH. Available at: http://www.smartpls.com

Salahshour Rad, M., Nilashi, M. and Mohamed Dahlan, H. (2018). Information technology adoption: a review of the literature and classification. Univ Access Inf Soc, 17, 361-390. https://doi.org/10.1007/s10209-017-0534-z

Scholtz, B. M., Kapeso, M. and de Villiers, M. R. R. (2017). The usefulness and ease of use of a mobile simulation application for learning of ERP systems. South African Computer Journal, 29(2), 87-105. https://doi.org/10.18489/sacj.v29i2.475

Seethamraju, R. (2007) Enterprise Systems (ES) Software in Business School Curriculum - Evaluation of Design and Delivery. Journal of Information Systems Education, 18(1) 69-84.

Sheu, C., Yen, H. R. and Krumwiede, D. W. (2003). The effect of national differences on multinational ERP implementation: an exploratory study. TQM \& Business excellence, 14(6), 641-657. https://doi.org/10.1080/1478336032000053807

Soto-Acosta, P., Ramayah, T. and Popa, S. (2013). Explaining intention to use an enterprise resource planning system: A replication and extension. Tehnicki Vjesnik, 20(3), 397-405.

Sternad, S. and Bobek, S. (2013). TAM-based external factors related to ERP solutions acceptance in organizations. International Journal of Information Systems and Project Management, 1(4), 25-38. https://doi.org/10.12821/IJISPM010402

Strong, J., Fedorowicz, J., Sager, G., Stewart G. and Watson, E. E. (2006). Teaching with Enterprise Systems, Communications of the Association for Information Systems, 17(33). https://doi.org/10.17705/1CAIS.01733

Venkatesh, V. (2000). Determinants of peceived easy of use: Integrating control, intrinsic motivation, and emotion into the Tecnology Acceptance Model. Information Systems Research, 11(4), 342-365. https://doi.org/10.1287/isre.11.4.342.11872

Venkatesh, V., Morris, M., Davis, G. and Davis, F. (2003). User Acceptance of Information Technology: Toward a Unified View. MIS Quarterly, 27(3), 425-478. https://doi.org/10.2307/30036540

Vluggen, M. and Bollen, L. (2005). Teaching enterprise resource planning in a business curriculum. Int. J. Information and Operations Management Education, 1(1), 44-57. https://doi.org/10.1504/IJIOME.2005.007447

Wong, K. K. (2010). Handling small survey sample size ans skewed dataset with partial least square path modellin. The Magazine of Marketing Research and Intelligence Association, 20-23. 


\section{APPENDIX A}

\section{Instrument}

The following Likert scale was used:

1. Completely agree

2. Mostly agree

3. Somewhat agree

4. Neither agree or disagree

5. Somewhat disagree

6. Mostly disagree

7. Completely disagree

Table 11. The items associated with the constructs

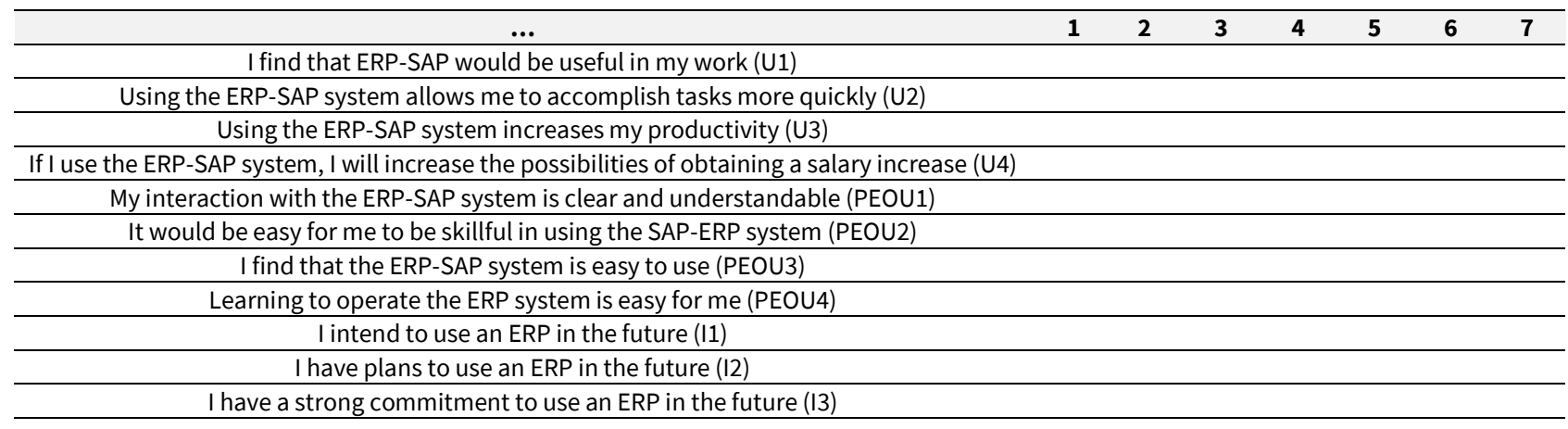

